\title{
Hermenêutica filosófica: um ensaio crítico sobre a proposta
} gadameriana

\section{Philosophical hermeneutics: a critical essay on the gadamerian proposal}

Hermenéutica filosófica: un ensayo crítico sobre la propuesta gadameriana

Victor Hugo de Oliveira Marques ${ }^{1}$

${ }^{1}$ Doutor em Desenvolvimento Local pela Universidade Católica Dom

Bosco (UCDB). Docente e coordenador do Curso de Filosofia da UCDB. E-mail: vicgo@bol.com.br, ORCID: http://orcid.org/0000-0002-4366-6596 
RESUMO: O presente ensaio pretende: [a] analisar se a proposta de uma Hermenêutica Filosófica, tal como pensou Gadamer, realmente dá conta do fundamento de toda e qualquer hermenêutica; e [b] avaliar a pertinência ou não do locus da filosofia para a hermenêutica. Para atingir esse objetivo, é cogente: [a] evidenciar que a História do Conceito (Begriffsgeschichte) não é capaz de traduzir um núcleo comum de significação para o termo Hermenêutica; [b] reconstruir os argumentos que tornam possível a expressão gadameriana Hermenêutica Filosófica; [c] levantar questões que apresentem a fraqueza central do argumento desde a propriedade especulativa hegeliana, lembrada pelo próprio Gadamer. Este artigo é, por um lado, pesquisa bibliográfica - já que se baseia em referências já consolidadas -, e, por outro, documental, na medida em que pretende revisitar alguns documentos importantes para o resultado. Essencialmente, a discussão é formalmente feita com Gadamer (2008) em seu tratado "Verdade e Método", o que não impedirá o uso de clássicos da história da Hermenêutica, como: Aristóteles (2016), Schleiermacher (1999), Dilthey (1900), Heidegger (1997, 1999) e o tratado "Ciência da Lógica", de Hegel (2016), como contraponto. Os resultados preliminares deste artigo problematizam a ideia de Hermenêutica Filosófica e lançam mão da teoria especulativa hegeliana como uma saída para o problema gadameriano.

Palavras-chave: Hermenêutica Filosófica; Gadamer; Hegel.

ABSTRACT: This essay intends to: [a] analyze if the proposal of a Gadamer's Philosophical Hermeneutics really gives an account of the foundation of any and all hermeneutics; and [b] to evaluate the relevance or not of the locus of philosophy for hermeneutics. Therefore, it is necessary: [a] to evidence that the History of the Concept (Begriffsgeschichte) is disabled of offer a common core of meaning to the term Hermeneutics; [b] to reconstruct the arguments that make the Gadamerian expression Philosophical Hermeneutics possible; [c] to raise questions that present the central weakness of the argument from the Hegelian speculative property that was remembered by Gadamer himself. On the one hand, this essay is a bibliographic research - since it is based on consolidated references-, and, on the other, a documentary, as it intends to revisit some important documents to contribute to the outcome. Essentially, the essay discussion is done formally with Gadamer (2008) in his treatise "Truth and Method", which will not prevent the use of classics from the history of Hermeneutics, such as: Aristotle (2016), Schleiermacher (1999), Dilthey (1900), Heidegger (1997, 1999), and the treatise "Science of Logic", by Hegel (2016), as a counter point. The preliminary results of this essay call into question the idea of Philosophical Hermeneutics and it use the Hegelian speculative theory as an outlet for the Gadamerian problem.

Keywords: Philosophical Hermeneutics; Gadamer; Hegel.

RESUMEN: Este ensayo tiene como objetivo: [a] analizar si la propuesta de una Hermenéutica Filosófica, como pensaba Gadamer, realmente da cuenta de los fundamentos de todas y cada una de las hermenéuticas; y [b] evaluar la relevancia o no del locus de la filosofía para la hermenéutica. Para lograr este objetivo, es necesario: [a] mostrar que la Historia del Concepto (Begriffsgeschichte) no es capaz de ofrecer un núcleo común de significado al término Hermenéutica; [b] reconstruir los argumentos que hacen posible la expresión gadameriana Hermenéutica Filosófica; [c] plantear cuestiones que presentan la debilidad central del argumento de la propiedad especulativa hegeliana, recordada por el propio Gadamer. Este ensayo es, por un lado, investigación bibliográfica - ya que se basa en referencias consolidadas -, y, por otro, documental, una vez que intenta revisar algunos documentos importantes para el resultado. Esencialmente, la discusión se hace formalmente con Gadamer (2008) en su tratado "Verdad y Método", lo que no impedirá el uso de clásicos de la historia de la hermenéutica, como: Aristóteles (2016), Schleiermacher (1999), Dilthey (1900), Heidegger $(1997,1999)$ y el tratado "Ciencia de la Lógica", de Hegel (2016), como contrapunto. Los resultados preliminares de este artículo problematizan la idea de la hermenéutica filosófica y utilizan la teoría especulativa hegeliana como una salida para el problema gadameriano.

Palabras clave: Hermenéutica Filosófica; Gadamer; Hegel. 


\section{INTRODUÇÃO}

Este artigo pretende: [a]analisar se a proposta de uma Hermenêutica Filosófica, tal como pensou Hans-Georg Gadamer, realmente dá conta do fundamento de toda e qualquer hermenêutica; e [b] avaliar a pertinência ou não do locus da filosofia para a hermenêutica. Para atingir estes objetivos, é cogente percorrer o seguinte caminho: em primeiro lugar, deverá ser evidenciado que uma História do Conceito (Begriffsgeschichte) não é capaz de traduzir um núcleo comum de significação para o termo Hermenêutica. Há, desde suas origens, um problema conceitual claramente aberto. Daí a relevância de revistar os ditos "lugares" a partir dos quais a hermenêutica historicamente repousou; em outras palavras, identificar seus possíveis "horizontes" ${ }^{2}$ históricos. Dentro destes horizontes, será destacada a chamada Virada Linguística- momento histórico da filosofia a partir do qual se permitiu a identificação da filosofia com a hermenêutica.

Dentro deste primeiro quadro de problemas, será possível reconstruir os principais argumentos formais que dão a Gadamer a certeza da factibilidade de uma Hermenêutica Filosófica. Sem dúvida, a reconstrução aqui pretendida da proposta hermenêutica de Gadamer está mais para uma análise formal de seus objetivos do que uma analítica de profundidade. É mais uma análise formal geral do modo como sua lógica foi construída e

${ }^{2} \mathrm{O}$ termo horizonte aqui se refere ao modo como Husserl o utiliza. De modo geral, há dois modos usados por este filósofo para dizer de horizonte. Do ponto de vista noético, também chamado de imanente ou inerente à consciência, a ideia de horizonte diz respeito às relações intencionais que um ato tem com outro, conferindo certa unidade a estes. Por exemplo, um ato de percepção que neste exato momento faz aparecer um objeto está intencionalmente ligado ao ato de percepção imediatamente anterior a ele e posterior a ele. Estas relações intencionais entre estes atos de percepção de um objeto formam um horizonte de sentido. Reconheço um objeto como idêntico, graças ao horizonte temporal que faz os atos perceptivos estarem intencionalmente referenciados. Mas, de outro lado, Husserl fala de um horizonte noemático ou externo à consciência. Neste sentido, horizonte são todos os dados que aparecem no ato perceptivo, mas não estão sendo tematizados no momento. Tudo que envolve e permite o aparecimento de um objeto aparecer, seu contexto não tematizado, é seu horizonte (DRUMMOND, 2007). No presente trabalho, o que se pretende é tematizar justamente o fundo da hermenêutica que não é tematizado, noematicamente falando. Ou seja, pretende-se mostrar todas aquelas relações que sustentam os sentidos hermenêuticos em sua construção histórica que são pouco ou quase sempre pressupostas. 
como, por meio dela, pôde-se alcançar a justaposição, por assim dizer, destes dois termos: Hermenêutica e Filosofia. Com esta expressão, Gadamer não apenas sugere uma mera similitude entre os termos, mas uma necessária e suficiente fusão, a qual faz mostrar a real natureza tanto da filosofia quanto da hermenêutica e sua função de fundamentação para a hermenêutica enquanto tal. De posse dos argumentos gadamerianos, aí, sim, surgirá o limite de seu pensamento. Este está assentado na base da conexão entre hermenêutica e filosofia, qual seja, na discussão da propriedade especulativa da linguagem que Gadamer recupera da dialética de Hegel.

De modo geral, tem-se aqui uma "pesquisa básica" ${ }^{3}$, que usa um método, desde o ponto de vista "de seus fins", explicativo. Em vista de seus "procedimentos", ela é uma pesquisa bibliográfica, por um lado - já que se baseia em referências já consolidadas -, e, por outro, uma pesquisa documental, na medida em que pretende revisitar alguns documentos importantes para o resultado. Essencialmente, a discussão é com Gadamer (2008) em seu tratado "Verdade e Método", o que não impedirá o uso de clássicos da história da Hermenêutica, como: Aristóteles (2016), Schleiermacher (1999), Dilthey (1900), Heidegger (1997; 1999) e o tratado "Ciência da Lógica", de Hegel (2016), como contraponto.

Os resultados preliminares deste ensaio apontam na direção de dois fatos: é totalmente factível que a filosofia e a hermenêutica estabeleçam algum tipo de relação; porém, é necessário previamente determinar "uma filosofia" e "uma hermenêutica" - o que põe em questão a tranquilidade desta relação. Estes dois fatos, por seu turno, abrem dois problemas: [a] somente uma filosofia deslocada para a linguagem deve ser reconhecida como o locus da hermenêutica? [b] Que estatuto epistemológico teria uma Hermenêutica Filosófica a fim de dar conta tanto da filosofia quanto das possíveis hermenêuticas? Estas duas indagações, de algum modo, não deixam de levantar suspeitas sobre a proposta de Gadamer. Esclarecer tais suspeitas e como elas podem pôr limites no pensamento de Gadamer é o que a análise final procurará fazer.

\footnotetext{
3 "Objetiva gerar conhecimentos novos, úteis para o avanço da Ciência, sem aplicação prática prevista. Envolve verdades e interesses universais" (GERHARDT; SILVEIRA, 2009, p. 34).
} 


\section{PROBLEMAS INERENTES ÀS ORIGENS DO TERMO HERMENÊUTICA}

É muito comum definir hermenêutica simplesmente por "interpretação". Vários dos estudiosos da história da hermenêutica a definem, por outro lado, como "ato de compreender" (SCHLEIERMACHER, 1988; DILTHEY, 1957; HEIDEGGER, 1997); ou como "teoria da interpretação" (GRONDIN, 1999; JEANROND, 1991; SCHMIDT, 2014). Não obstante, na verdade, a "[...] história da hermenêutica não é idêntica à história do termo hermenêutica" (JEANROD, 1991, p.12). Ainda que a palavra grega "E $\rho \mu \eta v \varepsilon \alpha^{\prime}$ " esteja na raiz do campo conceitual moderno denominado, hermenêutica, a prática a qual esse termo se refere é tão antiga quanto qualquer prática cultural humana.

Ora, quando se vai ao encontro da etimologia da palavra hermenêutica, nota-se que sua raiz é o verbo grego 'E $\rho \mu \eta v \varepsilon v \varepsilon \iota v$, que se refere às dimensões linguísticas mais básicas da comunicação humana, como: expressar (dizer, falar), expor (interpretar, explicar) e traduzir (ser intérprete) (GRONDIN, 1999; PALMER, 1969; JEANROD, 1991). Com efeito, uma primeira constatação aparece: desde suas raízes linguísticas, não existe uma significação comum. Esta inconsistência originária permite que o conceito sofra um processo histórico-evolutivo. Ao revisitar a história do conceito hermenêutica, este problema latente não se dirime; pelo contrário, ele se agrava - o que evidencia a insuficiência do uso do método História do Conceito (Begriffsgeschichte) $^{4}$ para alcançar ou determinar uma ideia nuclear.

Ademais, não estaria completo este movimento de recuperação etimológica do termo Hermenêutica se não tocasse em sua face obscura e mitológica a qual suas origens remontam. Durante muito tempo, circulou em algumas literaturas especializadas da Hermenêutica a tese de que o termo Hermenêutica é relativo ao nome do deus Hermes, o mensageiro dos deuses (HEIDEGGER, 1999). Entre elas, está o texto de Jearond (1991, p.1, tradução nossa).

Por 'hermenêutica' queremos dizer a teoria da interpretação. A palavra contém uma referência a Hermes, o mensageiro dos deuses na mitologia grega. A tarefa de Hermes era explicar aos humanos as decisões e os planos dos deuses. Assim, ele preenchia a lacuna entre

\footnotetext{
${ }^{4}$ Cf. as propostas de F. Meinecke, W. Dilthey, O. Brunner, E. Rothacker.
} 
o reino divino e humano. Similarmente, a hermenêutica preocupa-se em examinar a relação entre dois reinos: o reino de um texto ou obra de arte, por um lado, e a pessoa que deseja compreendê-lo, por outro.

Entretanto, Heidegger (1999) mesmo afirma que, por falta de referências, é difícil delimitar as reais origens da palavra Hermenêutica. Em suma, tudo isso indica que deverá haver outro modo de acessar tal termo, caso se queira melhor explorá-lo, do que o método etimológico.

\section{OS “LUGARES” DA HERMENÊUTICA}

A ausência de precisão em suas origens, bem como em seu processo histórico de evolução, pode dar uma falsa noção de que a hermenêutica incorre em uma contradição clássica de inconsistência. Alguém poderia dizer que seria necessária uma hermenêutica que conseguisse interpretar o que é hermenêutica; o que seria um sofisma de petitio de principii (pressupor como evidente aquilo mesmo que devia ser explicado). Uma alternativa é: recuperar os "lugares" 5 ou horizontes (por assim dizer) cujo termo Hermenêutica é dependente. Assim, em vez de buscar historicamente seus conceitos, o olhar seria redirecionado para os "ambientes", "horizontes" ou mesmo "lugares" por meio dos quais o termo pode ser desenvolvido. Tais lugares, na verdade, devem ser assumidos como "horizontes fenomenológicos" ${ }^{6}$ das significações hermenêuticas. Eles são como "campos de aparição", condições para que os termos possam aparecer e receber sentido e significado. Com efeito, ao se efetivar tal movimento, nota-se uma variação significativa de "lugares" vinculados ao seu uso e que não podem passar despercebidos.

\subsection{As narrativas mítico-sagradas}

O campo das narrativas mítico-sagradas pode ser considerado o primeiro horizonte em que a hermenêutica teve condições de ser gestada. É no interior das grandes tradições do passado humano, com destaque para

\footnotetext{
${ }^{5}$ Ricoeur também nota que existem certas "localidades" nas quais a hermenêutica procura se desenclavar. Cf. RICOEUR, P. Hermenêutica e ideologias, 2008.

${ }^{6}$ Cf. nota 1.
} 
a grega, de modo especial com os sofistas (posteriormente, com a filosofia estoica), que é possível encontrar os primórdios teóricos e práticos de uma hermenêutica. É mais do que claro que o termo Hermenêutica está sendo usado, aqui, no sentido de práticas rudimentares de compreensão, assimilação e interpretação da realidade circunvizinha. Dilthey (1957, p.7) escreveu a respeito:

A interpretação artística (kunstmäj3ige) ("hermenéia") dos poetas se desenvolveu na Grécia a partir da necessidade do ensino. No período do iluminismo grego um jogo espirituoso com a exposição e a crítica de Homero e de outros poetas era apreciado em todos os lugares onde se falava grego. Uma base mais firme surgiu quando, entre os sofistas e nas escolas dos retóricos, esta interpretação entrou em contato com a retórica. Isto porque nesta estava presente - aplicada à capacitação da oratória - a teoria mais geral da composição literária.

A hermenêutica, assim, surgiu como uma necessidade intrínseca aos textos mitológicos. O próprio estilo da narrativa mítica engendrou a prática de certos atos interpretativos. Os sofistas - que eram caracterizados pela habilidade em usar dos recursos da oratória e da retórica - recorriam à prática de decodificação dos textos míticos, com o intuito de questioná-los, o que os tornavam verdadeiras autoridades em seu tempo.

Os estoicos, por seu turno, propuseram-se a entender as narrativas míticas a partir de uma interpretação alegorizante 7 . Eles buscavam encontrar, atrás do chocante sentido literal, um significado mais profundo e até espiritual. Dilthey (1957, p. 9) escreveu:

Krates de Mallos trouxe da escola estóica o princípio da interpretação alegórica para a filologia de Pérgamo. O poder duradouro deste procedimento de interpretação estava fundamentado inicialmente no fato de que ela nivela a contradição entre documentos religiosos e uma visão de mundo refinada. Assim ela foi igualmente necessária para os intérpretes dos vedas, de Homero, da Bíblia e do Corão: uma arte tão imprescindível quanto inútil.

\footnotetext{
7 "A expressão $\alpha \lambda \lambda \eta \gamma_{0} \rho \iota \alpha$ provém, propriamente, da Retórica e foi cunhada por um gramático, o Pseudo-Heráclito (1ㅇséc. D.C.). Ele definiu a alegoria como um 'tropos' retórico, que possibilita dizer algo e, ao mesmo tempo, aludir a algo diverso" (GRONDIN, 1999, p. 59).
} 
Logo, eles desenvolvem uma prática interpretativa tendo por base três grandes razões: [1] eliminar aquilo que soasse escandaloso, absurdo ou contraditório nos mitos; [2] mostrar que o desenvolvimento de um pensamento racional acerca do mundo era plenamente conciliável com aquilo que era dito nos mitos; e, [3] por fim, não rejeitar a autoridade que os antigos poetas ainda possuíam.

De modo geral, o primeiro horizonte desvelado apresenta uma forte presença de um estilo literário bem específico, qual seja, o texto mítico-sagrado. Este horizonte é fundamental para justificar o surgimento da necessidade hermenêutica, já que a estilística mítico-sagrada é propriamente um convite para o acesso interpretativo. Suas obscuridades e metáforas alegóricas incidem decisivamente sobre o entendimento do texto, forçando o hermeneuta a lançar mão de ferramentas que faça o texto dizer o que ele deveria ter dito e não disse. Desde os gregos antigos, passando pela tradição cristão-filosófica e alcançando a Reforma, a condição mitológica e hermética dos textos sagrados (sejam ele de matriz grega, judaica ou judaico-cristã) permitiu o revelar da hermenêutica. É sobre este horizonte que, pela primeira vez, se tomou consciência da coisa mais importante da hermenêutica: o mal-entendido. Em outras palavras, nem tudo o que se diz é o que se diz.

\subsection{A formalidade da linguagem: a "Gramática" e a Lógica}

Outro horizonte importante da hermenêutica é o das disciplinas associadas à estrutura formal da linguagem, que seria a gramática e a lógica. Aristóteles é o primeiro a compreender que a hermenêutica não é um instrumento à parte do discurso; ao contrário, ela é um discurso e, enquanto tal, deveria estar assentada sobre a lógica. Em seu texto, "Peri Hermeneías", o filosofo, já no título, assume a discursividade do termo hermeneías. Neste texto, o tema é a "proposição", objeto exclusivo desta investigação (ARISTÓTELES, 2016). Em outras palavras, hermenêutica, aqui, é necessariamente aquele tipo de discurso que deve se conformar às regras lógicas, no caso, da proposição.

Por outro lado, os estudos lógicos, com o passar do tempo, passaram a ser desenvolvidos ao lado dos estudos gramaticais. Com os teólogos 
protestantes Johann C. Dannhauer e Johann M. Chladenius (ambos do século XVII e XVIII), a hermenêutica pôde ganhar espaço nos textos não sagrados e, com efeito, passou a ser mais uma prática "crítica" com contornos de erudição linguística do que uma prática interpretativa propriamente dita, tal como ocorria com os textos sagrados. O ato hermenêutico pressupunha formalizar e estruturar o discurso escrito (texto) a fim de que ele se conformasse com os padrões da publicação, ou seja, tinha uma função crítica e gramatical. Por outro lado, a hermenêutica também começou a ser associada aos trabalhos de tradução e ganhou uma função filológica. De modo geral, ela era vista como uma espécie de trabalho de editoração dos livros a serem traduzidos e publicados (GRONDIN, 1999). Dilthey (1957, p. 11) escreveu sobre a mudança de horizonte da hermenêutica:

A partir do Renascimento, a interpretação e a constituição de suas regras entraram em um novo estágio. [...] E esta nova filologia, polimatia e crítica contava em grande parte somente com relatos e ruínas para trabalhar. Assim ela tinha de ser criativa e construtiva de uma nova maneira. Por isso a filologia, a hermenêutica e a crítica entraram em um estágio superior. [...] Ela forma duas correntes distintas, pois os escritos clássicos e os bíblicos eram as grandes forças que se buscava apropriar. A elaboração de regras clássico-filológicas se designava a si própria as criticas.

Porém, foi somente no século XIX, com o filósofo e teólogo alemão Friedrich D. E. Schleiermacher, que se conseguiu sistematizar com mais rigor o papel da gramática dentro da hermenêutica. Em suas palavras:

A interpretação gramatical é superior quando se olha para a linguagem desde a extensão pela qual ela determina o pensamento de todo indivíduo; porém desde que se olhe a pessoa individual como o local da linguagem e seu enunciado como aquilo que a linguagem revela em si mesma (SCHLEIERMACHER, 1988, p.10, tradução nossa).

Para Schleiermacher, é fundamental no ato de compreensão de um texto a tomada de consciência das estruturas gerais e particulares que formam a linguagem utilizada pelo texto. Essa tomada de consciência destes elementos é o que ele chama de critério gramatical da interpretação. A linguagem é a extensão desde a qual o pensamento é conformado e determinado. Muito embora Schleiermacher (1988) formule a máxima hermenêutica 
de que compreender um autor é compreendê-lo melhor que ele mesmo (critério psicológico da hermenêutica), o autor nunca será maior que sua linguagem. O autor é sempre o local da manifestação da linguagem, e sua mensagem é o universal, a qual se deve levar em conta.

Em suma, tal como no primeiro horizonte, o segundo se mostrou como a condição de possibilidade para que uma hermenêutica (em sentido mais estrito) pudesse ser efetivada. Em primeiro lugar, este horizonte incluiu o ato interpretativo dentro do discurso. A hermenêutica não é um recurso linguístico, mas é um discurso e deve ser compreendida desde os elementos que o compõem. Esta inclusão eliminou do ato interpretativo as especulações subjetivas próprias das alegorias. O mal-entendido deve ser resolvido dentro do próprio discurso, dentro da linguagem, e não fora dela. A passagem da aplicação do ato interpretativo dos textos sagrados para qualquer tipo de textos e deve à percepção dos elementos lógicos e gramaticais do discurso hermenêutico. Interpretar deve seguir a mesma lógica, as mesmas regras e as mesmas preocupações estilísticas dos discursos. Ademais, incluiu-se no trabalho do hermeneuta a função de tradutor, abrindo espaços para a filologia. Em linhas gerais, este horizonte tornou a hermenêutica mais susceptível ao espírito do rigor das ciências modernas.

\subsection{A Virada Linguística e o caminho para uma Hermenêutica Filosófica}

Embora Dannhauer tenha sido o primeiro a considerar a ideia de uma hermenêutica universal ${ }^{8}$, é com Scheiermacher que a hermenêutica passou por um processo que, segundo Ricoeur (2008), se caracteriza pela superação da restrição a "Iocalidades" específicas. Esse movimento da hermenêutica Ricoeur (2008, p. 24, grifo do autor) denominou de "Desregionalização", definindo-o como uma preocupação em "ampliar progressivamente a visada da hermenêutica, de tal modo que todas as hermenêuticas regionais sejam incluídas numa hermenêutica geral". Contudo, não antes da Virada Linguística essa universalização foi realmente alcançada, tal como vai afirmar Gadamer (2008).

\footnotetext{
${ }^{8}$ Cf., 1630 fordert der Theologe und philosoph Johann Conrad Dannhauer in seiner Schrift Idea boni interpreti (Die Idee der guten Interpreten) erstmals den Enwurf einer solchen universalen Auslegenkunst" (LÖSENER, 2006, p. 27).
} 
O termo Virada Linguística foi usado pelo filósofo norte-americano Richard Rorty no título de um ensaio por ele organizado, "Linguistic Turn. Essays in philosophycal method", e se refere ao movimento feito pela Filosofia em direção à linguagem, nos seus termos:

A proposta do presente volume é oferecer materiais para a reflexão sobre a mais recente revolução filosófica, a da filosofia linguística. Por filosofia linguística, quero dizer a visão de que os problemas filosóficos são problemas que podem ser resolvidos (ou dissolvidos) ou pela reforma da linguagem, ou por uma melhor compreensão da linguagem que usamos (RORTY, 1992, p.3, tradução nossa) ${ }^{9}$.

Vale ressaltar que não se trata da descoberta, no século XX, da importância da linguagem, porque a linguagem já era discutida e fazia parte dos temas debatidos por vários intelectuais em tempos anteriores. A mudança está no fato de que, especialmente a partir de autores como Wittgenstein, a segunda fase do pensamento de Heidegger e Gadamer, os autores não só discutem acerca da linguagem, mas ela se torna o fundamento e o horizonte em que a reflexão filosófica acontece e é possível.

\section{O DESAFIO DE UMA HERMENÊUTICA FILOSÓFICA}

Hans-Georg Gadamer é, sem dúvidas, aquele que se deterá mais diretamente sobre a sistematização de uma hermenêutica qualificada como filosófica. Já no subtítulo de seu maior tratado, Verdade e Método, lê-se: "Traços fundamentais de uma Hermenêutica Filosófica". Seu desafio, em breves linhas, era duplo: levar a termo o ideal lançado por Schleiermacher de uma hermenêutica universal ${ }^{10}$ e dar à filosofia seu moto próprio. Sobre o primeiro, Gadamer (2008) está convencido de que a tradição hermenêutica já continha os elementos necessários, apenas não tinha condi-

\footnotetext{
${ }^{9}$ The purpose of the present volume is to provide materials for reflection on the most recent philosophical revolution, that of linguistic philosophy. I shall mean by "linguistic philosophy" the view that philosophical problems are problems which may be solved (or dissolved) either reforming language, or by understanding more about the language we presently use.

${ }^{10}$ Schleiermacher (1988, p. 5) constata: "Hermenêutica como a arte de compreender não existe ainda numa maneira geral, há de fato apenas várias formas específicas de hermenêuticas".
} 
ções suficientes para solucionar a questão. Gadamer (2008) percebe que a tradição já havia encontrado a chave da questão hermenêutica: a ideia de compreensão, porém ela não avançou pela dicotomia sujeito-objeto muito presente nessa tradição, em especial nas ciências do espírito. Por isso, somente com o deslocamento da filosofia para a linguagem é que foi possível aparecer o real sentido da compreensão. Nos termos de Gadamer (2008, p.559):

Já na análise da hermenêutica romântica tivemos ocasião de ver que a compreensão não se baseia em um deslocar-se para o interior do outro, em uma participação imediata de um no outro. Compreender o que alguém diz é, como já vimos, pôr-se de acordo sobre a coisa, não deslocar-se para dentro do outro e reproduzir suas vivências. Já destacamos que a experiência de sentido, que ocorre desse modo na compreensão, encerra sempre um momento de aplicação. Percebemos agora que todo este processo é um processo lingüístico. Não é em vão que a verdadeira problemática da compreensão e a tentativa de dominá-la pela arte - o tema da hermenêutica - pertence tradicionalmente ao âmbito da gramática e da retórica.

Uma das primeiras intuições de Gadamer é que "o problema hermenêutico não é, pois, um problema de domínio correto da língua, mas de correto acordo sobre um assunto, que se dá no medium da linguagem" (GADAMER, 2008, p. 499). Compreender não é nem se conformar com o espírito do autor (conhecendo melhor do que ele mesmo), nem se identificar com a experiência intersubjetiva do autor, muito menos fazer saltar aos olhos a ipsissima vox (a objetividade da estrutura linguística); compreender é entrar em "acordo" dentro da linguagem. A linguagem se apresenta como o medium em que a vida humana acontece e é possível ser entendida. Todos os movimentos da Razão, como conhecer, questionar, compreender, interpretar, dão-se dentro da linguagem, porque todos os entes, independentemente da forma, têm linguagem e se expressam por meio dela (GADAMER, 2008). Por isso, Gadamer defende que

[...] a linguagem não é somente um dentre muitos dotes atribuídos ao homem que está no mundo, mas serve de base absoluta para que os homens tenham mundo, nela se representa mundo. Para o homem, o mundo está aí como mundo numa forma como não está para qualquer 
outro ser vivo que esteja no mundo. Mas, esse estar aí do mundo é constituído pela linguagem (GADAMER, 2008, p. 571, grifo do autor).

É pertinente entender que, para Gadamer, a linguagem constitui o único modo possível de relação entre o ser humano e o mundo e, por isso mesmo, há a possibilidade de compreendê-lo (hermenêutica). Porque a linguagem não é apenas mera capacidade humana, mas sim a maneira como o mundo "aparece" para o ser humano. Gadamer (2008, p. 643, grifos nossos) escreve: "Temos de perseguir um pouco mais a relação de linguagem e mundo, se quisermos ganhar um horizonte adequado para a linguisticidade da experiência hermenêutica".

Mas como o horizonte linguístico contribuiria para o desafio de Schleiermacher? Gadamer (2008) explica que a linguagem, como medium, como centro da experiência humana, não deve ser lida como uma cópia da realidade, uma "representação". Essa experiência recupera duas tradições filosóficas: a ideia de linguagem e verdade no pensamento tardio de Heidegger e a ideia de logos especulativo no pensamento de Hegel. A discussão sobre a verdade desde a perspectiva heideggeriana de "acesso imediato ao ser" (a-letheia), por meio da linguagem estética, permitiu a Gadamer (2008, p.675) compreender também que a linguagem tem uma dimensão especulativa:

Engatando num uso terminológico atestado por Hegel, podemos chamar ao que é comum à dialética metafísica e à hermenêutica de especulativo [...] É especulativo quem não se entrega direta ou indiretamente à solidez dos fenômenos ou à determinação fixa do que se opina, mas que sabe refletir - hegelianamente falando, que reconhece o 'em si' como um 'para mim'. E uma ideia é especulativa, quando a relação que nela é enunciada não se deixa pensar como atribuição inequívoca de uma determinação a um sujeito, de uma propriedade à cada coisa dada, mas que tende ser pensada como uma relação especular, na qual o próprio espelhar não é nada mais do que a pura aparência do refletido, tal como o um é um do outro e o outro é o outro do um.

A retomada da leitura dialética hegeliana especulativa não é uma retomada a uma propriedade subjetiva ou transcendental; é, na verdade, aceitar que o logos especulativo, na sua qualidade especular/espelhar, permite 
transcender qualquer mediação entre a linguagem e o ser. Este modo de compreender a linguagem a devolve e a reconcilia com a realidade, pois “a própria linguagem tem algo de especulativo" (GADAMER, 2008, p. 679).

E acrescenta Gadamer (2008, p. 687, grifos do autor):

O ser que pode ser compreendido é linguagem. O fenômeno hermenêutico devolve aqui a sua própria universalidade à constituição ôntica do compreendido, quando a determina, num sentido universal, como linguagem, e determina sua própria referência ao ente, como interpretação.

Portanto, a possibilidade da compreensão da vida humana na relação com o mundo só é confirmada mediante a linguagem (GADAMER, 2008), já que o ser a ser compreendido é o ser que é compreendido como linguagem. E, nessa reflexão, está o fundamental da Hermenêutica.

Mas ainda falta o segundo desafio: como a hermenêutica e a filosofia se fundem? Gadamer (2008) compreende que a hermenêutica, enquanto compreensão (linguagem), seria muito restringida muito ficando apenas na ordem da filologia ou de outra ciência qualquer. A universalidade da linguagem na experiência ôntica do mundo não permite que a hermenêutica se restrinja tanto, o que incorre dizer que a hermenêutica tem sua vocação atrelada à verdade das coisas. Ora, a compreensão de verdade para Gadamer (2008) tem por base a compreensão de verdade heideggeriana: o acesso imediato ao ser mediante a abertura da arte. Assim, novamente a vocação hermenêutica pela verdade toca na linguagem. E nada mais verdadeiro do que conceber que a vocação pela verdade é específica da filosofia, assim a hermenêutica gadameriana nada mais é do que a própria filosofia.

\section{ANÁLISE E CONSIDERAÇÕES FINAIS}

Na tentativa de se definir o termo Hermenêutica, surge antecipadamente um problema dito hermenêutico - ou seja, da escolha de critérios para exercer a atividade mediadora da compreensão. Contudo, esse "problema" não invalida sua investigação, relegando-o a um petitio de principii, como aparentemente se mostra. Tal como Heidegger (1997) já havia levantado em "Ser e Tempo" a respeito da circularidade da pergunta pelo 
ser, o mesmo ocorre com problema hermenêutico; e a solução não pode eximir-se de uma análise para além de uma mera lógica formal. Em vista de tais dificuldades é que este artigo revisita a proposta gadameriana de uma Hermenêutica Filosófica sob dois aspectos: até que ponto a hermenêutica é um elemento filosófico e até que ponto ela dá conta de todas as outras. É claro que a análise aqui desenvolvida em cima da proposta gadameriana não pode ser tomada em profundidade, sem ulteriores revisões. O que aqui se pretende é, mediante um olhar formal, mostrar que há alguns limites que, a nosso ver, não foram considerados por Gadamer.

Independentemente do modo como se explicam as origens do uso do termo, é interessante destacar que a hermenêutica é encarada, desde os seus inícios, como um medium, ou seja, como mediação. O que também não seria estranho à filosofia ser pensada do mesmo modo. Assim, não é difícil afirmar que tanto a hermenêutica como a filosofia são mediações, aberturas que permitem acessar aspectos mais profundos da realidade. É fato, portanto, que hermenêutica e filosofia têm toques importantes uma para outra. Questionar a aproximação entre hermenêutica e filosofia não é a questão propriamente dita, mas dizer que a hermenêutica é a filosofia primeira, sim, é a questão.

Tal como foi visto, não há um consenso entre o "hermenêutico" em si (por assim dizer), muito menos, ao se olhar para a história da filosofia, haveria um consenso sobre o "filosófico" em si. Por ironia, essa ausência consensual é um elemento que os aproximam. Hermenêutica e Filosofia estão em relação intencional muito mais do que uma relação formal. Por outro lado, a proposta gadameriana pretende mostrar "desde dentro" como ambos são o mesmo; mas, para tanto, escolhas devem ser assumidas. Para Gadamer, como foi visto, o que une a filosofia e a hermenêutica é a experiência da linguagem. A hermenêutica é linguagem, pois a determinação da compreensão é linguagem; e a filosofia é linguagem, pois a vocação filosófica da busca pela verdade se daria desde o modo de ser da arte (linguagem), que expõe imediatamente as coisas como elas são - tese já defendida por Heidegger e assumida por Gadamer (2008). Filosofia e Hermenêutica são linguagens e, portanto, são universais e fundam as demais ciências. 
Do ponto de vista da Hermenêutica, a aproximação com a linguagem é legítima. A recuperação dos lugares hermenêuticos na história dá uma ideia da inclinação que o ato de interpretar sempre teve com os discursos de modo geral. Ainda que o modo como Gadamer lida com a linguagem seja específico do modo de fazer filosofia na era contemporânea, a linguagem é um componente exequível da hermenêutica. Agora, pode-se dizer o mesmo da filosofia?

É importante lembrar que a linguagem nem sempre teve o mesmo tratamento e valor que o dado pelas análises atuais, qual seja, estar em uma relação mais de fundamento do que uma relação instrumental. Rorty (1992) fala que este modo de lidar com a linguagem é uma "nova revolução". Gadamer (2008) mostra claramente que a compreensão da linguagem tal como ele concebe é fruto de mudanças históricas de compreensão. Ou seja, houve, querendo ou não, a ação de uma nova hermenêutica sobre o modo de notar tanto a linguagem como a filosofia na história. Ora, diriam alguns, mas isso não provaria que na base de tudo há uma hermenêutica agindo, contribuindo para a tese de Gadamer?

Por outro lado, poder-se-ia indagar: o que ou quem determina o modo de compreensão verdadeiro da ação hermenêutica? Por quais razões o momento histórico presente seria o mais adequado para determinar o que é linguagem, a fim de sistematizar Filosofia e Hermenêutica? Determinar o papel de ambos (Filosofia e Hermenêutico) como o mais verdadeiro - tal como faz Gadamer, elegendo o modo atual de entender a linguagem como o horizonte possível a ambos - parece muito arbitrário e não vence uma perspectiva historicista própria das ciências do espírito. É possível crer que somente uma hermenêutica cuja determinação está alinhada a um modo de compreender o "compreender" como linguagem seria capaz de se universalizar? E somente uma filosofia deslocada em linguagem seria capaz de fundir-se em uma compreensão hermenêutica?

Em nosso ver, a proposta de uma Hermenêutica Filosófica, à luz da compreensão formal (da hermenêutica) gadameriana, seria em tese insuficiente e não conseguiria vencer o historicismo das ciências do espírito. É fato, como dissemos, que Hermenêutica e Filosofia se tocam e são convergentes intencionalmente. Porém, essa convergência está mais para uma 
argumentação apofática (negativa) do que por uma determinação. É fato também que há na base de toda a realidade uma ação hermenêutica. $E$ essa ação hermenêutica - tendemos a concordar com Gadamer - tem um elemento especulativo da dialética hegeliana. Assim como Hegel, para evitar o problema do começo, não quis determinar o "saber" e o "ser", também na base da realidade há tanto um "hermenêutico" indeterminado, quase nada, quanto uma "intencionalidade pela verdade".

Nesse sentido, Hegel, que pretendia a universalidade sem cair na finitude historicista, notou que determinar o começo seria muito arriscado, para não dizer arbitrário. Em seus termos:

Apenas em época mais recente, surgiu a consciência de que há uma dificuldade em encontrar um início na filosofia e o fundamento dessa dificuldade, bem como a possibilidade de solucioná-la, foi discutido de modo variado. O início da filosofia precisa ser ou algo mediato ou algo imediato e é fácil mostrar que ele não pode ser nem um nem outro; então, ambos os modos de iniciar encontram sua refutação (HEGEL, 2016, p. 53).

Em seu texto sobre o começo - Com que precisa ser feito o início da ciência? - que está nas páginas iniciais de seu tratado sobre lógica, Hegel argumenta que o início é também o fim, e o fim é também o início: "[...] o essencial para a ciência não é tanto que algo puramente imediato seja o início, mas que o todo da mesma seja um ciclo [kreislauf] dentro de si mesmo, onde o primeiro também é o último e o último é o primeiro" (HEGEL, 2016, p.56). Embora Gadamer sustente o aspecto especulativo de Hegel, sua preocupação com as determinações iniciais não é atentada por Gadamer. Acreditamos que a pergunta pelo começo de Hegel, tal como foi acima citada, e sua preocupação com as determinidades são válidas e devem incidir na hora de interpor filosofia e hermenêutica, caso creia-se que a filosofia esteja inclinada por uma linguagem de matriz especulativa.

Mais do que admitir uma fundamentação, melhor seria admitir: ou que não haja determinações possíveis para o princípio hermenêutico; ou que a natureza da hermenêutica não é filosófica, mas multidisciplinar - não só de disciplinas, mas de várias realidades que a compõem (subjetividade, objetividade, historicidade, realidade etc.). 


\section{REFERÊNCIAS}

ARISTÓTELES. Da interpretação. 3.ed. São Paulo: Edipro, 2016. (Coleção Órganon).

DILTHEY, W. Die Entstehung der Hermeneutik (1900). Numen: Revista de Estudos e Pesquisa da Religião, Juiz de Fora, v. I, n. 1, p. 11-32, 1998.

DRUMMOND, J. J. Historical Dictionary of Husserl's Philosophy: Historical dictionaries of religions, philosophies, and movements. Lanham: Scarecrow Press, 2007.

GADAMER, H. G. Verdade e método. Tradução de Flávio Paulo Meurer; revisão da tradução Enio Paulo Giachini. 10. ed. Petrópolis: Vozes, 2008.

GERHARDT, T. E.; SILVEIRA, D. T. (Org.). Métodos de pesquisa. Porto Alegre: Editora da UFRGS, 2009.

GRONDIN, J. Introdução à hermenêutica filosófica. Tradução de Benno Dischinger. São Leopoldo: Ed. Unisinos, 1999.

HEGEL. Ciência da lógica. Petrópolis: Vozes, 2016. V.I.

HEIDEGGER, M. Ser e tempo - parte I. Tradução de Márcia de Sá Cavalcante. Petrópolis: Vozes, 1997.

HEIDEGGER, M. The traditional concept of hermeneutics. In: Ontology - the hermeneutics of facticity. Tradução de John van Buren. Bloomington, Indiana: Indiana University Press, 1999. p. 6-11.

JEANROND, W. G. Theological hermeneutics: development and significance. London: MacMillan, 1991.

LÖSENER, H. Zwischen wort und wort: interpretation und textanalyse. Müncher: WFV, 2006.

PALMER, R. Hermeneutics. Evanston: Northwestern University Press, 1969.

RICOEUR, P. Hermenêutica e ideologias. Tradução de Hilton Japiassu. 3. ed. Petrópolis: Vozes, 2008.

RORTY, R. (Ed.). Linguistic Turn. Essays in philosophical method. Chicago, London: University of Chicago Press, 1992. 
SCHLEIERMACHER, F. Hermeneutics and Criticism. And other writings. Cambridge: Cambridge University Press, 1988.

SCHMIDT, L. K. Hermenêutica. Tradução de Fábio Ribeiro. 3. ed. Petrópolis: Vozes, 2014. 
